\title{
Oxalate-Templated Synthesis of Di-Zinc Macrocycles
}

Jeffrey W. Beattie, ${ }^{a}$ Daniel J. SantaLucia, ${ }^{\text {a, b }}$ David S. White, ${ }^{\text {a, c }}$ and Stanislav Groysman ${ }^{\text {a }}$

${ }^{a}$ Department of Chemistry, Wayne State University, 5101 Cass Ave, Detroit, MI, 48202.

${ }^{b}$ Present Address: Hope College, 141 E 12th St, Holland, MI 49423

${ }^{c}$ Present Address: Department of Neuroscience, University of Wisconsin-Madison, 1101 University Ave, Madison, WI 53706

Keywords: template synthesis, oxalate, macrocycle, zinc complexes

(C) 2016. This manuscript version is made available under the Elsevier user license http://www.elsevier.com/open-access/userlicense/1.0/ 


\begin{abstract}
Herein we report that oxalate serves as a template in the formation of di-zinc macrocycles featuring bis(imino)pyridine chelating units linked by $p$-xylylene or $m$-xylylenes linkers. The resulting complexes were characterized by NMR spectroscopy, mass spectrometry, elemental analysis, and X-ray crystallography. NMR spectroscopy indicates highly symmetrical $\left(C_{2 \mathrm{v}}\right.$ or $D_{2 \mathrm{~h}}$ ) structures of the macrocyclic complexes in solution. Solid-state structures, determined by X-ray crystallography (obtained only for the $m$-xylylene bridged macrocycles), revealed hexacoordinate zinc centers with $\mu^{2}-\kappa^{2}, \kappa^{2}$-bound oxalate, meridional NNN chelates, and an additional ligand (DMF or $\mathrm{H}_{2} \mathrm{O}$ ) bound to zinc centers. Cyclic voltammetry demonstrates series of reductions associated with the redox-active bis(imino)pyridine chelates; no oxidation was observed up to $1 \mathrm{~V}$. We have attempted to extract oxalate from the macrocycle using calcium bromide, ethylenediaminetetraacetic acid (EDTA), trimethyl silyl chloride (TMSCl), acetic acid, or hydrochloric acid $(\mathrm{HCl})$. Of the above, EDTA, TMSCl, acetic acid, and $\mathrm{HCl}$ in ether failed to remove oxalate or to form a new isolable product, while calcium bromide transformed $\mu^{2}-\kappa^{2}, \kappa^{2}-$ bound oxalate into the $\mu^{2}-\kappa^{1}, \kappa^{2}$-bound form. The addition of aqueous $\mathrm{HCl}$ enables observation of the oxalate-free complex by mass spectrometry as one of the major products.
\end{abstract}




\section{Introduction}

There is a significant interest in the synthesis of dinuclear metal complexes due, in part, to the possible metal-metal cooperativity in the activation of small molecules and catalysis. ${ }^{[1,2]}$ Macrocyclic ligands constitute particular useful frameworks for the stabilization of bimetallic and polymetallic complexes as they generally allow well-defined metal-metal distances which are paramount to a catalyst design. ${ }^{[2 a-c, 3]}$ Schiff-base containing macrocycles are relatively common. ${ }^{[4]}$ Their assembly, however, often relies on the use of templating agents, most commonly metal ions. ${ }^{[4]}$ In addition, some bridging ligands (for example, imidazole, acetate, or azide) capable of binding two metals have been used as templating agents in the formation of dinuclear macrocycles. ${ }^{[5,6]}$ Of all bridging ligands, oxalate is among the most common - a CSD search revealed ca. 4800 compounds containing bridging oxalate. Although oxalate is frequently encountered as a bridging ligand in bimetallic complexes, we are unaware of its use as a template to form macrocycles.

We are investigating dinuclear complexes featuring redox active chelating groups. One particular aspect of our research efforts focuses on the cooperative effects that such complexes may have in the activation of heteroallenes. ${ }^{[7]}$ Specifically, we are targeting dinuclear reductive coupling or reductive splitting of carbon dioxide and related heteroallenes, to yield oxalate or carbon monoxide, respectively. We have recently reported dinuclear di-Ni complexes supported by open-chain dinucleating ligands in which two iminopyridine chelates were linked by $p$ xylylene diamine. ${ }^{[7 \mathrm{a}-\mathrm{c}]}$ Some of these complexes were found to ligate two molecules of carbon disulfide per one molecule of dinuclear complex; $\eta^{2}$-bound carbon disulfide was reduced to the $\left[\mathrm{CS}_{2}\right]^{2-}$ state. ${ }^{[7 \mathrm{~b}, \mathrm{c}]}$ However, no cooperativity was observed between the reduced $\mathrm{CS}_{2}$ molecules. We postulated that the lack of reactivity resulted, among other reasons, from the highly flexible 
nature of these open-chain complexes. We have also demonstrated that these open-chain systems are capable of efficient and reversible binding of oxalate, with oxalate positioned in the intramolecular cavity, thus serving as chemosensors for oxalate. ${ }^{[7 d]}$ We decided next to pursue more rigid macrocyclic systems with two tridentate bis(imino)pyridine chelates linked by $p$ xylylene- or $m$-xylylenediamine linkers. We note that our previous (open-chain) systems incorporated $p$-xylylene linkers; thus, present work would be a direct extension of an open-chain system featuring one $p$-xylylene linker to a macrocyclic system containing two such linkers. As for the choice of $m$-xylylene linkers, similar macrocyclic systems bridged by a $m$-xylylene linker have been previously synthesized using imidazole. ${ }^{[6]}$ We decided to investigate oxalate as a template. The oxalate is the product of the reductive coupling of carbon dioxide. We hypothesized that a bimetallic system templated by oxalate would have the appropriate intramolecular cavity size for its binding and thus may facilitate its formation via reductive coupling. Herein we report successful oxalate-templated syntheses of di-zinc macrocycles and their structural, spectroscopic, and electrochemical characterization. The focus of this work on zinc chemistry is due to the fact that zinc(II) enables the use of NMR spectroscopy as an easily accessible characterization method for the products of the exploratory synthesis; following a success of zinc chemistry, it could be further extended to other transition metals. We also describe our endeavors to extract the oxalate from the di-zinc macrocycles, including the structure of the di-zinc complex containing asymmetrically bound partially removed oxalate.

\section{Results and Discussion}

\section{Synthesis of macrocycles 1-4}


Open-chain bis(iminopyridine) ligands can be synthesized by the addition of two equivalents of an aldehyde/ketone to the diamine in the absence of any templating agent. ${ }^{[6]} \mathrm{A}$ similar approach to the syntheses of the desired macrocycle employing various combinations of 2,6-pyridinedicarboxyadehyde/2,6-diacetylpyridine with para-xylylene ( $p$-xylylene) and metaxylylene ( $m$-xylylene) diamines failed to produce soluble products, which suggests that the desired macrocycles were not obtained (see Experimental for details). We were not able to characterize these products due to their lack of solubility in common organic solvents. We hypothesize that polymeric material was formed instead of the macrocycles.

Thus, we turned next to the template synthesis. Treatment of a solution of zinc triflate and tetrabutylammonium oxalate ${ }^{[7 b]}$ in methanol with solutions of 2,6-diformylpyrine (2,6pyridinedicarboxalydehyde) and $p$-xylylene diamine consecutively resulted in the formation of a cloudy solution. The solution was stirred at room temperature overnight, after which the volatiles were removed and the resulting white solid was washed with THF. Drying the product afforded the macrocyclic complex $\left[\left(\mathrm{Zn}_{2}\left(\mathrm{~L}^{1}\right)\left(\mathrm{C}_{2} \mathrm{O}_{4}\right)\right]\left(\mathrm{O}_{3} \mathrm{SCF}_{3}\right)_{2}(\mathbf{1})\right.$, containing bis(aldimino) chelates, in $79 \%$ yield. In contrast to the facile formation of the bis(aldimino)macrocycle linked by the $p$ xylylene bridge, the reaction of 2,6-diacetylpyridine with $p$-xylylene diamine failed to produce the corresponding bis(ketimino) macrocycle.

We have also investigated the formation of $m$-xylylene bridged macrocycles. Treatment of the mixture of zinc triflate with tetrabutylammonium oxalate in methanol with the solutions of 2,6-dicarboxypyridine and $m$-xylylene diamine forms the aldimino-based macrocyclic complex $\left[\left(\mathrm{Zn}_{2}\left(\mathrm{~L}^{2}\right)\left(\mathrm{C}_{2} \mathrm{O}_{4}\right)\right]\left(\mathrm{O}_{3} \mathrm{SCF}_{3}\right)_{2}\right.$ (2) isolated as a white solid in $86 \%$ yield. A similar reaction sequence using 2,6-diacetylpyridine instead of 2,6-dicarboxypyridine forms the macrocyclic complex $\left[\left(\mathrm{Zn}_{2}\left(\mathrm{~L}^{3}\right)\left(\mathrm{C}_{2} \mathrm{O}_{4}\right)\right]\left(\mathrm{O}_{3} \mathrm{SCF}_{3}\right)_{2}(\mathbf{3})\right.$ incorporating ketimino groups. Complex 3 was isolated 
as an orange solid in $73 \%$ yield. Thus, while the $p$-xylylene diamine linker enables only the formation of an aldimino-containing macrocycle, $m$-xylylene is capable of supporting both aldimino and ketimino macrocycles. The origin of this difference in reactivity is not entirely clear. One could speculate that in $p$-xylylene the amino nitrogens are further away from each other than in $m$-xylylene diamine and thus are less predisposed to support formation of small entropically unfavorable $2 \times 2$ macrocycles. While the more reactive formyl groups undergo facile condensation and cyclization with both $p$-xylylene diamine and $m$-xylylene diamine, the reaction is more sluggish with less electrophilic acetyl groups, and therefore only $m$-xylylene forms the desired $2 \times 2$ macrocycle.

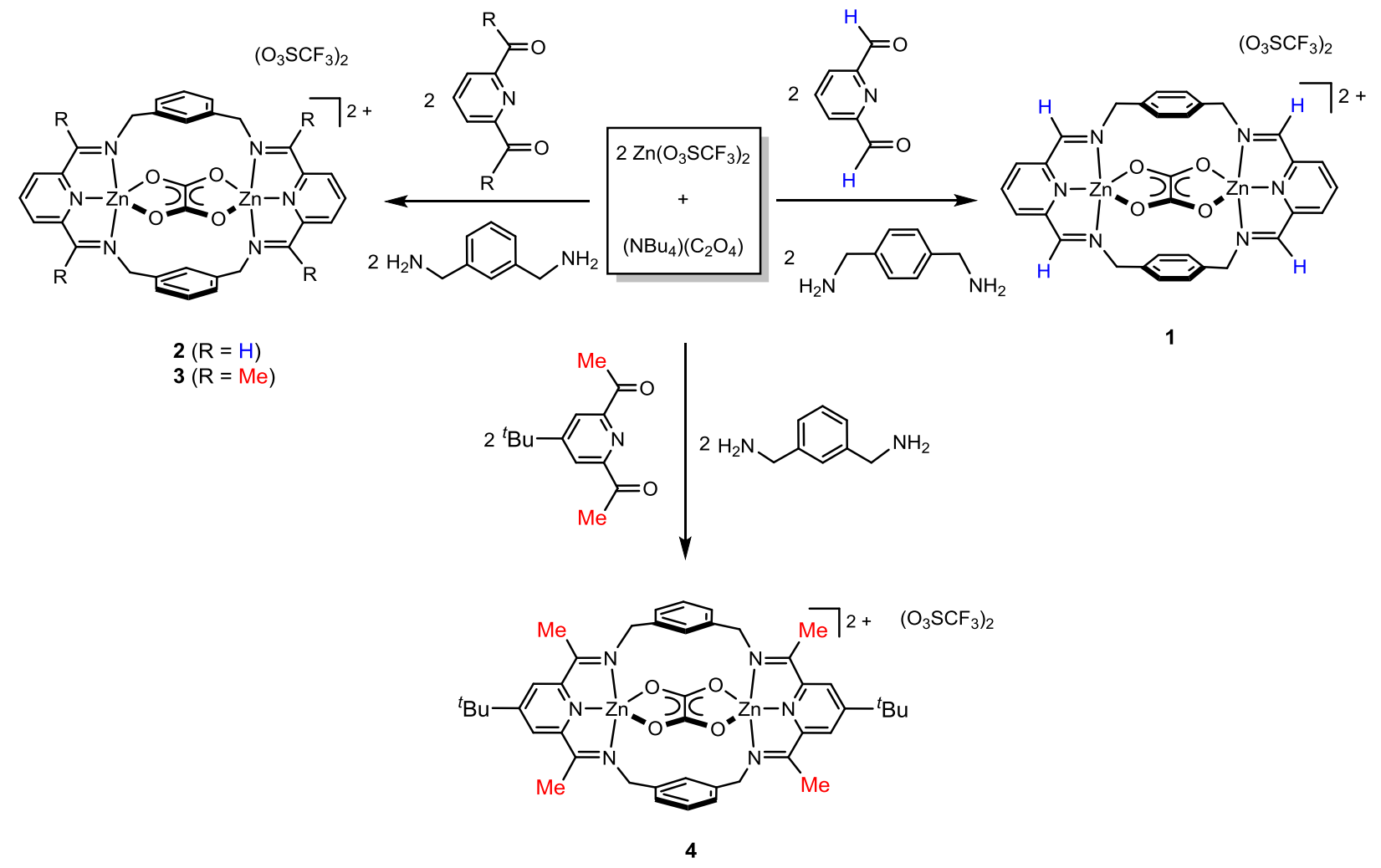

Scheme 1. Oxalate-templated synthesis of di-zinc macrocycles 1-4 
We note that this "template effect" in the formation of the di-zinc complexes of the bis(imino)pyridine macrocycles described above is selective for oxalate. We have carried out similar self-assembly reactions using zinc triflate, 2,6-diacetylpyridine, and $m$-xylylenediamine, combined with a variety of mono- and dicarboxylate salts, namely formate, acetate, succinate and malonate. In all cases, no macrocycle formation was observed, as indicated by ${ }^{1} \mathrm{H}$ NMR and mass spectrometry (see Experimental for details). We also note that Burrows and coworkers have previously synthesized one of the macrocycles $\left(\mathrm{L}^{3}\right)$ using di-copper and di-nickel imidazole templates. $^{[6]}$

Compounds 1-3 demonstrate only limited solubility in highly polar organic solvents (DMSO and DMF), are sparingly soluble in $\mathrm{CH}_{3} \mathrm{CN}$, and are completely insoluble in $\mathrm{THF}$, $\mathrm{CH}_{3} \mathrm{OH}$, and acetone. To improve the solubility of these macrocycles, we pursued the synthesis of the macrocycles featuring ${ }^{t} \mathrm{Bu}$ groups in the para position of pyridine ring. Corresponding 2,6diacetyl-(4-tert-butyl)pyridine was prepared according to the previously published procedure. ${ }^{[8]}$ Subsequent condensation with $m$-xylylene diamine in the presence of zinc triflate/tetrabutylammounium oxalate formed complex 4 (Scheme 1) in 96\% yield. In spite of the ${ }^{t} \mathrm{Bu}$ groups, complex 4 demonstrated poor solubility in $\mathrm{CD}_{3} \mathrm{CN}$, therefore its spectra were collected in $\mathrm{CD}_{3} \mathrm{OD}$, in which it was sparingly soluble.

\section{Spectroscopic characterization of 1-4}

Complexes 1-4 were characterized by ${ }^{1} \mathrm{H}$ and ${ }^{13} \mathrm{C}$ NMR spectroscopy, mass spectrometry, cyclic voltammetry and elemental analysis. The ${ }^{1} \mathrm{H}$ NMR spectrum of complex $\mathbf{1}$, containing $p$ xylylene bridges, demonstrates sharp singlet for all (four) methylene protons at $4.90 \mathrm{ppm}$, a 
singlet for the aromatic protons of the $p$-xylylene bridge at $7.13 \mathrm{ppm}$, and one singlet for the four aldimino protons at $8.91 \mathrm{ppm}$. Similarly, the ${ }^{1} \mathrm{H}$ NMR spectra of the $m$-xylylene complexes $\mathbf{2 - 4}$ demonstrate one sharp singlet for the methylene protons at 4.87 (2), $4.85(\mathbf{3})$, and 3.85 (4, spectrum in $\mathrm{CD}_{3} \mathrm{OD}$ ) ppm. The Me groups of the ketimino-based compounds $\mathbf{3}$ and $\mathbf{4}$ appear as one singlet at $2.74 \mathrm{ppm}(\mathbf{3})$ and $2.80 \mathrm{ppm}(\mathbf{4})$. Thus, NMR spectra of 1-4 demonstrate effective $C_{2 \mathrm{v}}\left(D_{2 \mathrm{~h}}\right.$ for $\left.\mathbf{1}\right)$ symmetry in solution, consistent with penta-coordinate zinc centers, or with a fast dynamic process at the hexa-coordinate zinc centers found in the solid state (vide infra). Such dynamic process may involve loss of a labile ligand (solvent or counter-ion), formation of a penta-coordinate zinc center, and re-coordination of the labile ligand on the opposite side of the pyridine ring. ${ }^{13} \mathrm{C}$ NMR spectra of $\mathbf{1 - 4}$ all give rise to a single resonance for the methylene carbons, and a single resonance for the imino carbons.

To gain further insight into the structure of complexes 1-4 in solution, we conducted mass spectrometric studies. ESI-MS indicates that 1-4 are highly stable compounds in solution. Figure 1 illustrates the positive ion mode mass spectrum of compound 3. Both the unipositive ion $\left\{\left[\left(\mathrm{Zn}_{2}\left(\mathrm{~L}^{3}\right)\left(\mathrm{C}_{2} \mathrm{O}_{4}\right)\right]\left(\mathrm{O}_{3} \mathrm{SCF}_{3}\right)\right\}^{1+}\left\{3-\mathrm{O}_{3} \mathrm{SCF}_{3}\right\}\right.$ and the dipositive ion $\left\{\left[\left(\mathrm{Zn}_{2}\left(\mathrm{~L}^{3}\right)\left(\mathrm{C}_{2} \mathrm{O}_{4}\right)\right]\right)\right\}^{2+}\{$ 3$\left.\left(\mathrm{O}_{3} \mathrm{SCF}_{3}\right)_{2}\right\}$ are observed, being the dominant ions in the spectrum. Mass spectra of compounds 1 and 2 demonstrate similar features to that of 3: the dipositive ions for the isomeric compounds 1 and 2 are found at $\mathrm{m} / \mathrm{z}=343.03$, and the unipositive ions at $\mathrm{m} / \mathrm{z}=835.01$ (see SI). 


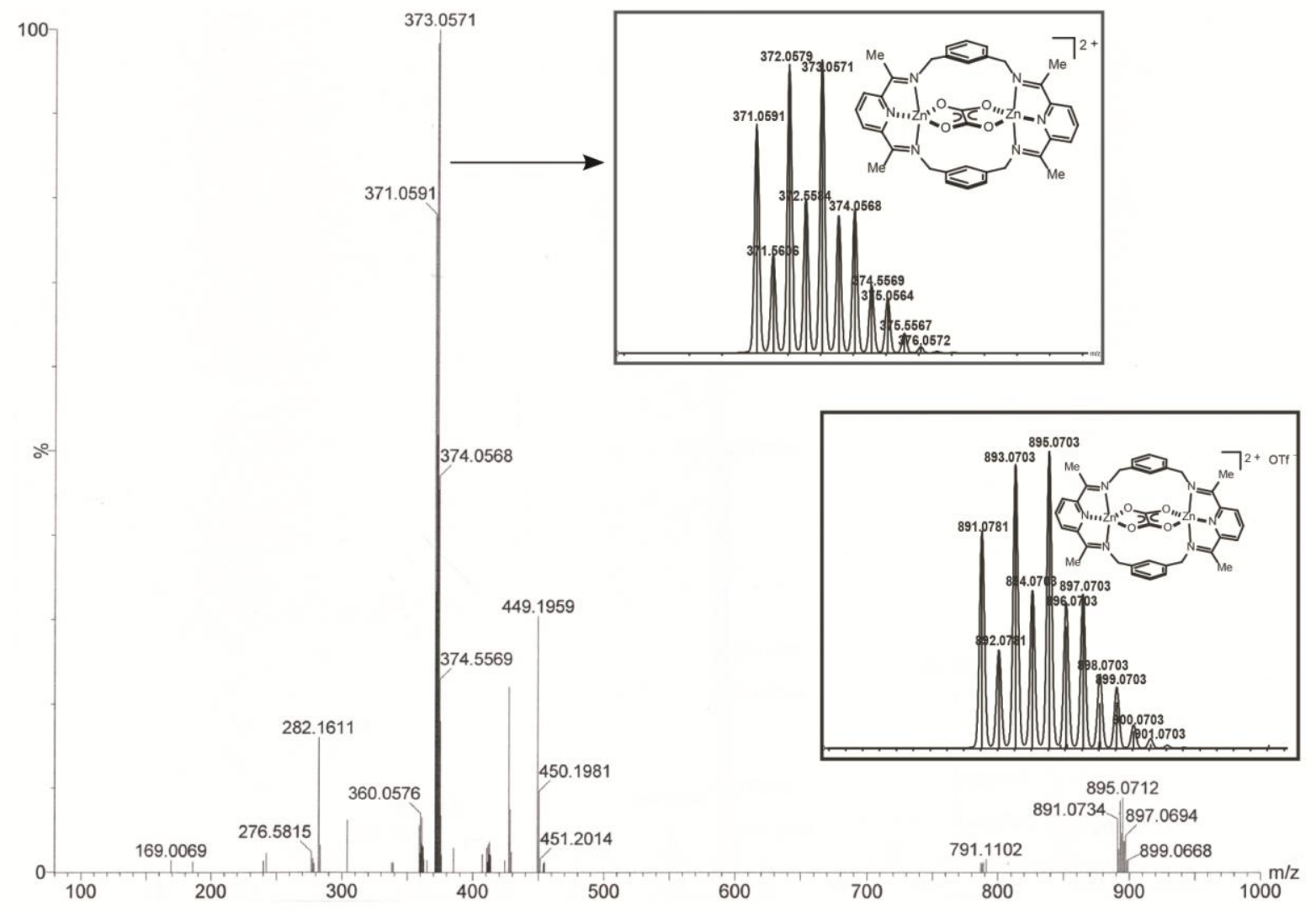

Figure 1. ESI-MS spectrum of compound 3; insets demonstrate peaks attributed to $\left\{\left[\left(\mathrm{Zn}_{2}\left(\mathrm{~L}^{3}\right)\left(\mathrm{C}_{2} \mathrm{O}_{4}\right)\right]\left(\mathrm{O}_{3} \mathrm{SCF}_{3}\right)\right\}^{1+}(\right.$ at $\mathrm{m} / \mathrm{z} 891.07)$ and $\left[\left(\mathrm{Zn}_{2}\left(\mathrm{~L}^{3}\right)\left(\mathrm{C}_{2} \mathrm{O}_{4}\right)\right]^{2+}(\right.$ at $\mathrm{m} / \mathrm{z} 371.06)$.

\section{X-ray structures of compounds 2 and 3}

Crystallization of compounds $\mathbf{2}$ and $\mathbf{3}$ by vapor diffusion of ether into a corresponding DMF solution yielded DMF-coordinating structures of $\mathbf{2}$ and $\mathbf{3}\left(\mathbf{2}-\mathrm{DMF}_{2}\right.$ and $\left.\mathbf{3}-\mathrm{DMF}_{2}\right)$ that were determined by X-ray crystallography. In addition to the structures of $2-\mathrm{DMF}_{2}$ and $3-\mathrm{DMF}_{2}$, we have also determined the structure of $\mathbf{2}-\left(\mathrm{OH}_{2}\right)_{2}$. The structure of $\mathbf{2}-\left(\mathrm{OH}_{2}\right)_{2}$ (obtained by slow evaporation of DMF) exhibits coordination of the water molecules instead of DMF. Curiously, 
unbound DMF co-crystallizes with the molecule of $\mathbf{2}-\left(\mathrm{OH}_{2}\right)_{2}$ as part of the unit cell. Our attempts to obtain X-ray quality crystals of $\mathbf{1}$ were unsuccessful.

The structures of $\mathbf{2}-\mathrm{DMF}_{2}$ and $\mathbf{3}-\mathrm{DMF}_{2}$ are given in Figures $\mathbf{3}$ and $\mathbf{4}$, respectively; the structure of 3-(OH$)_{2}$ is given in Figure 5. All three structures exhibit intramolecular coordination of oxalate in the bimetallic cavity. While such coordination of oxalate has been previously reported, ${ }^{[9]}$ these are the first examples of di-zinc complexes binding oxalate intramolecularly. The zinc centers are octahedral, featuring meridional coordination of bis(imino)pyridine chelates, oxalate oxygens, and the oxygen atoms of DMF ligands. The $\mathrm{Zn}-\mathrm{O}$ and $\mathrm{Zn}-\mathrm{N}$ bond distances in the structures of $\mathbf{2}-\mathrm{DMF}_{2}$ and $\mathbf{3}-\mathrm{DMF}_{2}$ are unremarkable, consistent with similar bonds previously reported. ${ }^{[10,11]}$ A noteworthy difference between the two structures involves the tighter and more symmetrical packing of $\mathrm{L}^{3}$ versus $\mathrm{L}^{2}$ (Figure 5). It is also worth noting that the asymmetric unit in the structure of $3-\mathrm{DMF}_{2}$ constitutes only half of the bimetallic complex $/ \mathrm{L}^{3}$ ligand versus the entire complex in the case of $\mathrm{L}^{2}$.

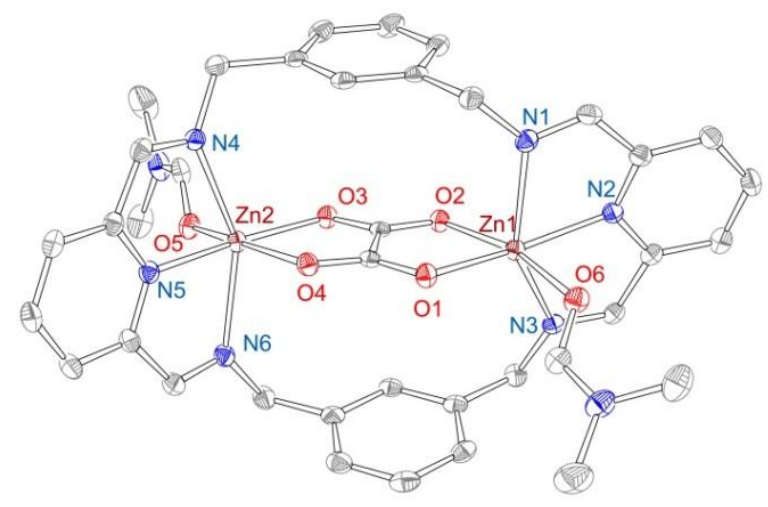

Figure 2. X-ray structure (50\% probability ellipsoids) of $2-\mathrm{DMF}_{2}$. Non-coordinating triflates and H-atoms are omitted for clarity. 


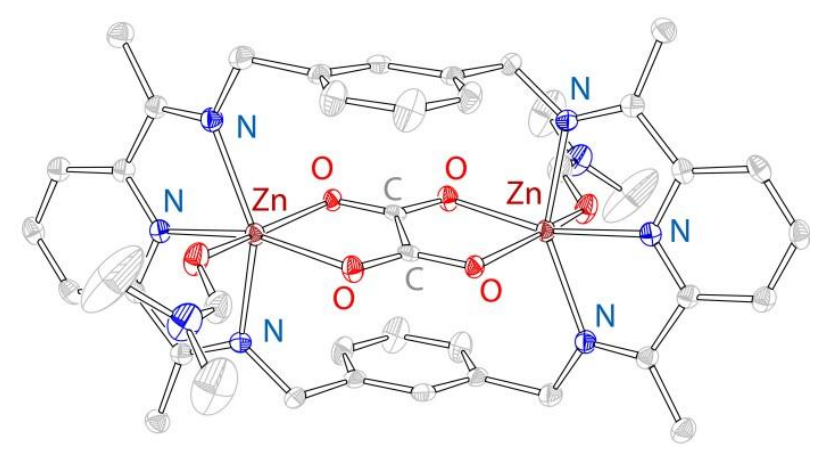

Figure 3. X-ray structure (50\% probability ellipsoids) of $\mathbf{3}-\mathrm{DMF}_{2}$. Non-coordinating triflates and H-atoms are omitted for clarity.

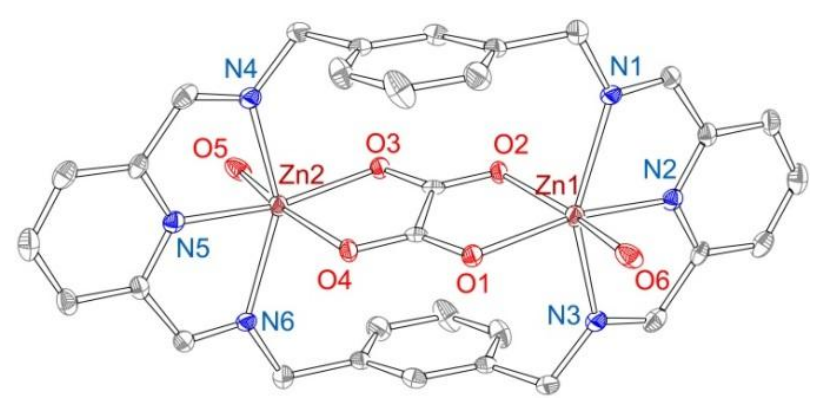

Figure 4. X-ray structure (50\% probability ellipsoids) of 2-( $\left(\mathrm{OH}_{2}\right)_{2}$. Non-coordinating triflates and DMF molecules, and H-atoms are omitted for clarity.
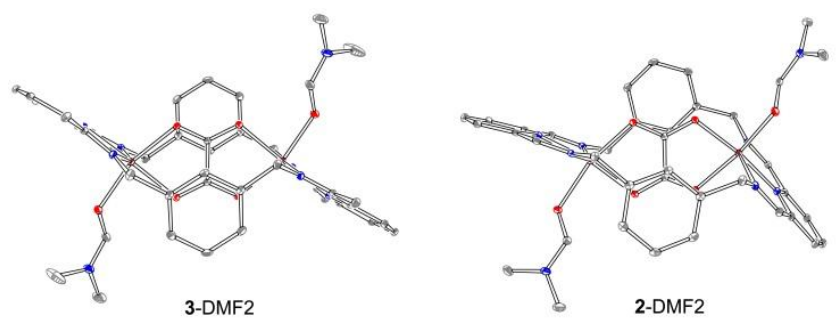

Figure 5. Comparison of the top views of the structures of $3-\mathrm{DMF}_{2}$ and $2-\mathrm{DMF}_{2}$ illustrating more symmetrical coordination of $\mathrm{L}^{3}$. 
Burrows and coworkers have reported a di-Cu(II) structure of $\mathrm{L}^{3}$ with bridging imidazolate. ${ }^{[6]}$ The differences between the $\mathrm{Zn}_{2}$-oxalate bridged structure of $\mathrm{L}^{3}$ and $\mathrm{Cu} 2$ imidazolate bridged structure are noteworthy. The zinc-oxalate structure is centrosymmetric, which implies "anti-parallel" arrangement of the bridging $m$-xylylenes (Figure 6, right). In contrast, the copper-imidazole structure is non-centrosymmetric (Figure 6, left). Furthermore, it features two distinct copper(II) centers, one binding triflate, and the other coordinating water. Due to the structural constraints imposed by the bridging imidazolate, the two di(imino)pyridine chelates are bent toward each other (angle between two [NNN] planes is approximately $120^{\circ}$ ). This, in turn, leads to the "syn-parallel" arrangement of the bridging xylylene units. Oxalate coordination, in contrast, imposes the angle of nearly $180^{\circ}$ between the [NNN] planes which in turn leads to the anti-parallel geometry of the $m$-xylylene bridges. In both cases, the two xylylene linkers and the bridging ligand, imidazolate or oxalate, form a "triple decker". However, while the "syn-parallel" arrangement in Burrows' complex leads to the imidazolate being sandwiched between xylylenes, the anti-parallel arrangement in the $\mathrm{Zn}$-oxalate systems leads to the ladderlike triple decker. We also note that Holland and coworkers reported related di-zinc complexes of bis(diketiminato) dinucleating ligands bridged by $p$-xylylene and $m$-xylylene linkers. Based on ${ }^{1} \mathrm{H}$ NMR spectroscopy and comparison with similar aluminum and lithium complexes, the authors postulated that their $\left[\mathrm{Zn}_{2}(\mathrm{~L}) \mathrm{Et}_{2}\right]$ complexes feature syn geometry in solution. In solid state, however, they also observed the anti-parallel geometry of the $m$-xylylene bridging units in the structure of the $m$-xylylene-bridged complex, $\left[\mathrm{Zn}_{2}(\mathrm{~L}) \mathrm{Et}_{2}(\mathrm{py})_{2}\right]{ }^{[12]}$ 


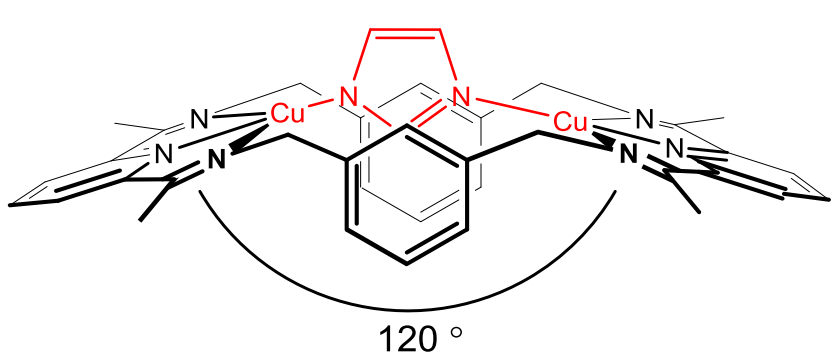

syn-parallel arrangement of xylylene linkers

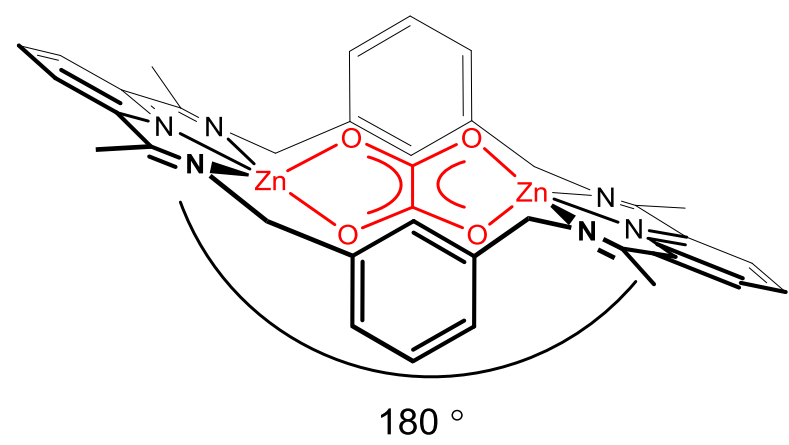

anti-parallel arrangement of xylylene linkers

Figure 6. Schematic drawing of the cores of the $\mathrm{L}^{3}$ complexes with imidazolate and oxalate linkers demonstrating different conformations of the macrocyclic ligand dictated by the structure of their template.

\section{Electrochemical characterization of compounds 1-3}

We have also investigated the electrochemical properties of compounds $\mathbf{1 - 3}$, seeking to answer two questions. First, compounds 1-3 feature redox-inactive metals $(\mathrm{Zn}(\mathrm{II}))$ that are ligated by redox-active ligands. Redox activity of mononuclear $\mathrm{Zn}$ (II) complexes in redox-active environments has been investigated, ${ }^{[13,}{ }^{14]}$ including recent electrochemical characterization of bis(imino)pyridine $\mathrm{Zn}$ (II) complexes and isolation of the reduced bis(imino)pyridine $\mathrm{Zn}$ (II) complexes by Berben and coworkers. ${ }^{[15]}$ We wanted to find out whether our complexes, featuring two bis(imino)pyridine units bridged by a $\left[\mathrm{Zn}_{2}\right.$ (oxalate)] bridge, also demonstrate reduction events associated with redox-active ligands. Second, we were interested in discovering whether oxalate can be removed from our complexes via oxidation. We note that oxidation of metal-bound oxalate to carbon dioxide has been previously reported. ${ }^{[16]}$ 
The cyclic voltammogram of $\mathbf{3}$ is given in Figure 7. Three reductions are observed, with the first two $(-1.6 \mathrm{~V}$ and $-2.0 \mathrm{~V})$ being quasi-reversible $\left(\Delta E_{\mathrm{p}}=0.15 \mathrm{~V}\right.$ and $0.13 \mathrm{~V}$, respectively). No accessible oxidations are detected up to $1.0 \mathrm{~V}$, therefore, we conclude that oxalate extraction via oxidation is not feasible in our system. The electrochemical features observed in the cyclic voltammogram are assigned to the redox-active nature of the bis(ketimino)pyridine ligands bound to the redox-inactive zinc. ${ }^{[15]}$ Interestingly, Berben and coworkers have also observed two redox events at the mononuclear bis(imino)pyridine zinc complex with the first event being irreversible due to chloride loss. In our case, the first event is reversible, likely due to the rigid structure of the oxalate-bridged $\left[\left(\mathrm{Zn}_{2}\left(\mathrm{~L}^{3}\right)\left(\mathrm{C}_{2} \mathrm{O}_{4}\right)\right]^{2+}\right.$ core unit. The bis(aldimino)pyridine-based compounds 1 and 2 demonstrate similar features (see SI for details) albeit somewhat less wellresolved. 

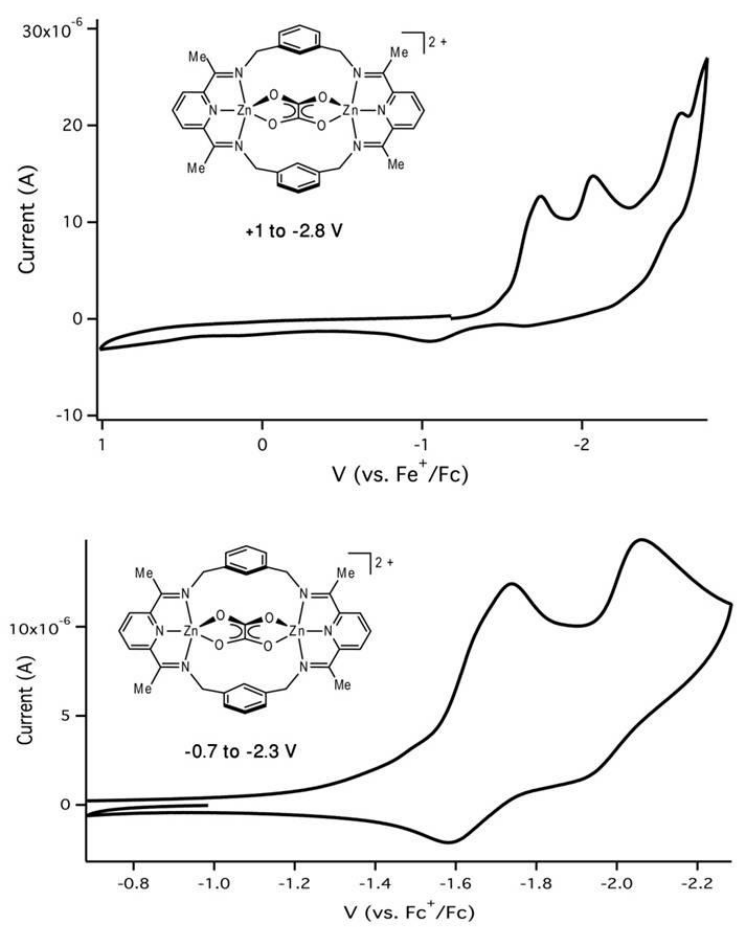

Figure 7. Top: Cyclic voltammetry of complex 3 in $1.0--2.8 \mathrm{~V}$ region. Bottom: cyclic voltammetry of complex 3 shown between -0.7 and $-2.3 \mathrm{~V}$. Conditions: DMSO, $0.1 \mathrm{M}$ $\left(\mathrm{PF}_{6}\right)\left(\mathrm{NBu}_{4}\right)$ supporting electrolyte, $100 \mathrm{mV} / \mathrm{s}$ scan rate.

\section{Oxalate Extraction Studies}

Following the synthesis and the characterization of the oxalate-templated complexes, we turned to investigate oxalate extraction. For the open-chain systems, we have previously reported that oxalate can be cleanly abstracted by the addition of calcium bromide, that forms insoluble calcium oxalate, along with a metal-bromide complex. ${ }^{[\mathrm{d}]}$ For the macrocyclic systems reported herein, this strategy failed to work. Treatment of complexes 1-4 with varying amounts of calcium bromide (2-20 equiv) leads to complex mixture of products. We were able to isolate the product of the reaction of $\left[\left(\mathrm{Zn}_{2}\left(\mathrm{~L}^{3}\right)\left(\mathrm{C}_{2} \mathrm{O}_{4}\right)\right]\left(\mathrm{O}_{3} \mathrm{SCF}_{3}\right)_{2}\right.$ (complex 3) with four equivalents of calcium 
bromide (complex 5, Figure 7), albeit in low yield. In complex 5, triflates are replaced by bromides, which then are coordinated to the zinc centers. As a result, oxalate switches to the asymmetric $\kappa^{2} / \kappa^{1}$ binding mode. This coordination mode of oxalate is significantly less common than the ubiquitous $\kappa^{2} / \kappa^{2}$ bridging mode, albeit not unprecedented: CSD revealed about 40 transition metal complexes featuring $\kappa^{2} / \kappa^{1}$ bridging mode, versus ca. 1000 complexes demonstrating $\kappa^{2} / \kappa^{2}$ bridging mode. ${ }^{[17]}$ In addition to the oxalate, two bromide ligands are bound to the metal centers. One of the metals is hexa-coordinate, displaying a distorted octahedral geometry. The other zinc is penta-coordinate, and demonstrates distorted trigonal pyramidal geometry, with the imino nitrogen being axial. The other noteworthy feature of the structure is the "pulled-back" conformation of the macrocyclic ligand $\left(\sim 12^{\circ}\right.$ angle between the $[\mathrm{NNN}]$ planes), that is considerably different from the conformation found in the parent $\left[\left(\mathrm{Zn}_{2}\left(\mathrm{~L}^{3}\right)\left(\mathrm{C}_{2} \mathrm{O}_{4}\right)\right]\left(\mathrm{O}_{3} \mathrm{SCF}_{3}\right)_{2}\right.$ species $\left(\sim 180^{\circ}\right.$ angle between the $[\mathrm{NNN}]$ planes $)$, or from the conformation found in Burrows' complex (Figure 6 above). This observation is in line with the observed conformational dependence of the macrocycle on the bridging ligand and its overall adaptivity. We note that despite the crystallographic evidence for the "partially extracted" asymmetrically-bound oxalate, ${ }^{1} \mathrm{H}$ NMR spectrum of complex 5 (see SI) is similar to the spectrum of compound $\mathbf{3}$, demonstrating symmetrical $\left(C_{2 \mathrm{~V}}\right)$ environment. Thus, it is likely that compound 5 loses bound bromide ligands and reverts to the more typical $\kappa^{2} / \kappa^{2}$ bridging mode of oxalate in solution. Due to the obtained low yield, low solubility, and overall spectral similarity to the other complexes, complex $\mathbf{5}$ was characterized only by X-ray crystallography, NMR spectroscopy, and HRMS. 


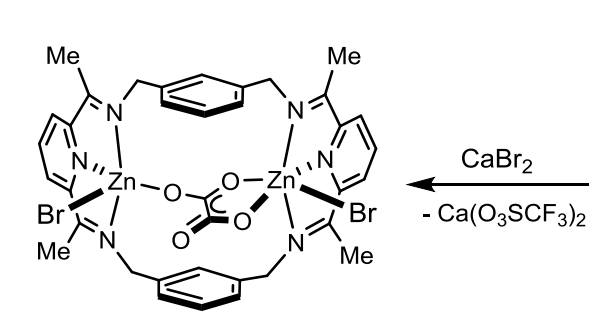

5, isolated and characterized by X-ray

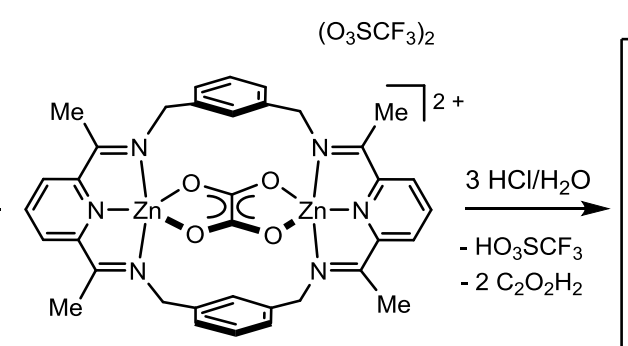

L

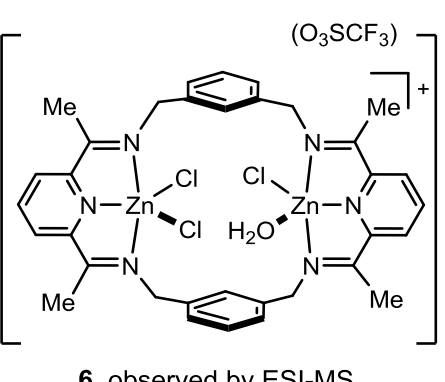

6, observed by ESI-MS

Scheme 2. Oxalate extraction reactions conducted on complex 3.

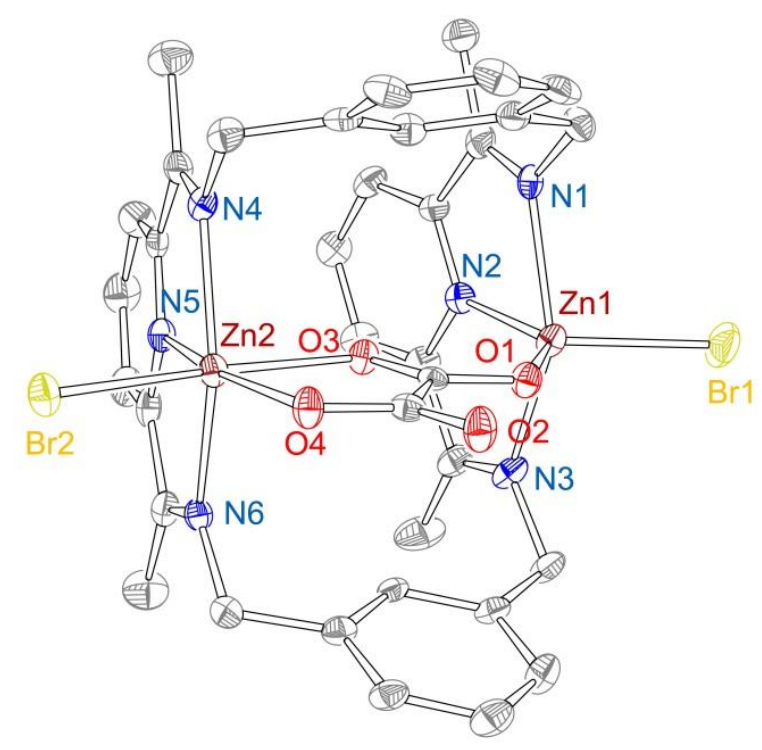

Figure 8. X-ray structure (50\% probability ellipsoids) of 5 . H-atoms are omitted for clarity.

As we were not able to achieve oxalate extraction using calcium bromide, we turned to investigate other methods, using complex $\mathbf{3}$ as an example. Burrows and coworkers reported that their $\left[\mathrm{Cu}_{2}(\text { imidazole })\right]^{4+}$ template from the identical ligand framework $\left(\mathrm{L}^{3}\right)$, was removed using EDTA. ${ }^{[6]}$ In the case of $\left[\left(\mathrm{Zn}_{2}\left(\mathrm{~L}^{3}\right)\left(\mathrm{C}_{2} \mathrm{O}_{4}\right)\right]\left(\mathrm{O}_{3} \mathrm{SCF}_{3}\right)_{2}\right.$, no reaction was observed upon treatment of the complex with EDTA. We attempted to remove oxalate via silylation; however, treatment of 
complex 3 with excess trimethylsilyl chloride failed to affect oxalate coordination. Similarly, the reaction of complex 3 with acetic acid or anhydrous $\mathrm{HCl}$ (in ether) failed to lead to new isolable products. Next, we explored the removal of oxalate using aqueous $\mathrm{HCl}$. The solution of $\left[\left(\mathrm{Zn}_{2}\left(\mathrm{~L}^{3}\right)\left(\mathrm{C}_{2} \mathrm{O}_{4}\right)\right]\left(\mathrm{O}_{3} \mathrm{SCF}_{3}\right)_{2}\right.$ was treated with $1.0 \mathrm{M} \mathrm{HCl}$ in water, and the resulting mixture was examined by ESI-MS. Figure 9 demonstrates formation of the $\left[\left(\mathrm{Zn}_{2}\left(\mathrm{~L}^{3}\right)\left(\mathrm{Cl}_{3}\right)\left(\mathrm{OH}_{2}\right)\right]^{+}\right.$ion as detected by ESI-MS. The signal attributed to the $\left[\left(\mathrm{Zn}_{2}\left(\mathrm{~L}^{3}\right)\left(\mathrm{Cl}_{3}\right)\left(\mathrm{OH}_{2}\right)\right]^{+}\right.$species is the major signal in the spectrum, along with the signals attributed to the starting material $(\mathrm{m} / \mathrm{z} 371.06$ and 891.07). We were not able to isolate " $\left[\left(\mathrm{Zn}_{2}\left(\mathrm{~L}^{3}\right)\left(\mathrm{Cl}_{3}\right)\left(\mathrm{OH}_{2}\right)\right]\left(\mathrm{O}_{3} \mathrm{SCF}_{3}\right)\right.$ " (compound 6) or any other product from this reaction in a pure state, likely due to the ensuing hydrolysis. However, these results demonstrate that although isolation of the clean product was not achieved, the extraction can be done in situ, which may lead to the use of $\left[\left(\mathrm{Zn}_{2}\left(\mathrm{~L}^{3}\right)\left(\mathrm{C}_{2} \mathrm{O}_{4}\right)\right]\left(\mathrm{O}_{3} \mathrm{SCF}_{3}\right)_{2}\right.$ and related oxalatetemplated compounds in catalytic applications.

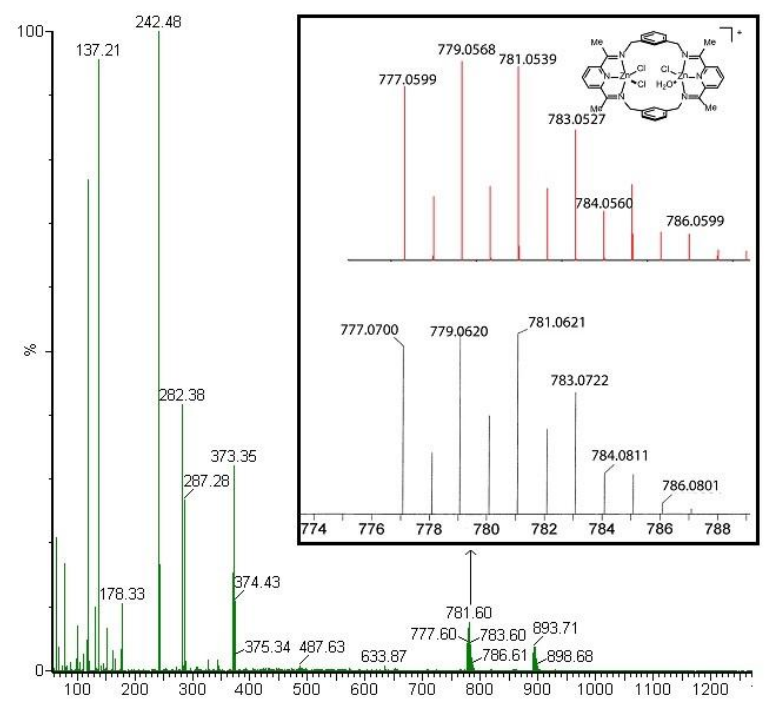

Figure 9. ESI-MS spectrum of the reaction mixture resulting by treating compound $\mathbf{3}$ with $\mathrm{HCl}$ demonstrating formation of $\left[\left(\mathrm{Zn}_{2}\left(\mathrm{~L}^{3}\right)(\mathrm{Cl})_{3}\left(\mathrm{OH}_{2}\right)\right]^{+}\right.$species (at $\mathrm{m} / \mathrm{z}$ 777.07), along with the starting 
materials at $\mathrm{m} / \mathrm{z} 891.07$ and $\mathrm{m} / \mathrm{z}$ 391.07. Inset top: high-resolution mass spectrum attributed to $\left[\left(\mathrm{Zn}_{2}\left(\mathrm{~L}^{3}\right)(\mathrm{Cl})_{3}\left(\mathrm{OH}_{2}\right)\right]^{+}\right.$species. Inset bottom: predicted mass spectrum of $\left[\left(\mathrm{Zn}_{2}\left(\mathrm{~L}^{3}\right)(\mathrm{Cl})_{3}\left(\mathrm{OH}_{2}\right)\right]^{+}\right.$.

\section{Summary}

In summary, we demonstrated that oxalate serves as a template in the formation of dizinc Schiff-base macrocycles, featuring bis(imino)pyridine chelating units linked by $m$-xylylenes or $p$-xylylenes. The presence of saturated $\mathrm{CH}_{2}$ linkages in the macrocyclic framework allows for the conformational flexibility of these macrocycles, which then can accommodate different bridging units or different binding modes of oxalate. Quasi-reversible and irreversible reductions were observed below $-1.7 \mathrm{~V}$, all associated with the redox-active bis(imino)pyridine chelates; no electrochemical oxidation was observed up to $1.0 \mathrm{~V}$ (vs. $\mathrm{FeCp}_{2} / \mathrm{FeCp}_{2}{ }^{+}$). Oxalate extraction proved difficult likely due to its chelating and anionic nature. Most of the reagents that were evaluated did not lead to any changes in the oxalate-bridged complex structure, while calcium bromide led to the transformation of $\kappa^{2}, \kappa^{2}$-bound oxalate into the $\kappa^{2}, \kappa^{1}$-bound form (in solid state) while adding bromides to the zinc centers. The use of aqueous hydrochloric acid formed $\left[\left(\mathrm{Zn}_{2}\left(\mathrm{~L}^{3}\right)(\mathrm{Cl})_{3}\left(\mathrm{OH}_{2}\right)\right]^{+}\right.$, as observed by mass spectrometry; however, the complex was not stable under acidic conditions and was not isolated in a pure form.

\section{Acknowledgements}

The authors thank Wayne State University for initially supporting this project and the National Science Foundation for the current support under grant number CHE-1349048.

\section{Experimental Section}




\section{General methods and procedures}

All reactions were executed under ambient conditions except for the reactions involving trimethylsylil chloride, which were done under nitrogen atmosphere. $p$-Xylylenediamine, $m$ xylylenediamine, 2,6-diacetylpyridine, 2,6-pyridinecarboxaldehyde, zinc triflate, oxalic acid, and tetrabutylammonium methoxide were purchased from Aldrich, Strem or TCI America and used as received. $\left[\mathrm{C}_{2} \mathrm{O}_{4}\right]\left(\mathrm{NBu}_{4}\right)_{2}$ was synthesized as previously described. ${ }^{[7 \mathrm{~d}]}$ All solvents were purchased from Fisher scientific and were of HPLC grade. The solvents were purified using an MBRAUN solvent purification system and stored over 3 - $\AA$ molecular sieves. Compounds were routinely characterized by ${ }^{1} \mathrm{H},{ }^{13} \mathrm{C}\{\mathrm{H}\}$ NMR $\left({ }^{13} \mathrm{C}\right.$ NMR thereafter $)$ and ${ }^{19} \mathrm{~F} \mathrm{NMR}$, X-ray crystallography, and elemental analyses. Selected compounds were characterized by mass spectrometry (ESI). NMR spectra for all the compounds were recorded at the Lumigen Instrument Center (Wayne State University) on a Varian Mercury 400 NMR Spectrometer in $\mathrm{CD}_{3} \mathrm{CN},\left(\mathrm{CD}_{3}\right)_{2} \mathrm{SO}$, and $\mathrm{CD}_{3} \mathrm{OD}$ at room temperature. Chemical shifts and coupling constants $(J)$ are reported in parts per million $(\delta)$ and Hertz respectively. Low resolution mass spectra were obtained at the Lumigen Instrument Center utilizing a Waters Micromass ZQ mass spectrometer (direct injection, with the capillary at $3.573(\mathrm{KV})$ and a cone voltage of $20.000(\mathrm{~V})$ ). Only selected peaks in the mass spectra are reported below. Elemental analyses were performed by Midwest Microlab LLC.

\section{Synthesis and Characterization of Compounds}

$\left[\left(\mathbf{Z n}_{2}\left(\mathbf{L}^{\mathbf{1}}\right)\left(\mathbf{C}_{2} \mathbf{O}_{4}\right)\right]\left(\mathbf{O}_{3} \mathbf{S C F}_{3}\right)_{2}\right.$ (compound 1) - To a $20 \mathrm{~mL}$ solution of zinc triflate (278 $\mathrm{mg}, 0.765 \mathrm{mmol})$ in $\mathrm{MeOH}$ a $20 \mathrm{~mL}$ solution of $\left[\mathrm{C}_{2} \mathrm{O}_{4}\right]\left(\mathrm{NBu}_{4}\right)_{2}(218 \mathrm{mg}, 0.383 \mathrm{mmol})$ in $\mathrm{MeOH}$ was added and allowed to stir for 5 min at which point a $20 \mathrm{~mL}$ solution of 2,6- 
pyridinedicarboxalydehyde (112 $\mathrm{mg}, 0.765 \mathrm{mmol})$ was added. The resulting solution was stirred for $5 \mathrm{~min}$ at which point $p$-xylylenediamine was added $(104 \mathrm{mg}, 0.765 \mathrm{mmol})$. The resulting solution was allowed to stir for $12 \mathrm{~h}$ yielding a cloudy solution. The solvent was removed under reduced pressure to form a white solid. This solid was then washed with $200 \mathrm{~mL}$ of THF for $1 \mathrm{~h}$. The resulting slurry was filtered and a white solid collected as pure $\left[\left(\mathrm{Zn}_{2}\left(\mathrm{~L}^{1}\right)\left(\mathrm{C}_{2} \mathrm{O}_{4}\right)\right]\left(\mathrm{O}_{3} \mathrm{SCF}_{3}\right)_{2}\right.$ $(0.299 \mathrm{~g}, 79 \%) .{ }^{1} \mathrm{H}$ NMR $\left(\mathrm{CD}_{3} \mathrm{CN}, 400 \mathrm{MHz}\right) \delta 8.91(\mathrm{~s}, 4 \mathrm{H}), 8.44(\mathrm{t}, J=8.0 \mathrm{~Hz}, 2 \mathrm{H}), 8.11(\mathrm{~d}, J$ $=8 \mathrm{~Hz}, 4 \mathrm{H}), 7.13(\mathrm{~s}, 8 \mathrm{H}) 4.90(\mathrm{~s}, 8 \mathrm{H}) \mathrm{ppm} .{ }^{13} \mathrm{C} \mathrm{NMR}\left(\mathrm{CD}_{3} \mathrm{CN}, 75 \mathrm{MHz}\right) \delta 160.20,147.54$, 145.33, 136.02, 130.74, 130.28, 63.60 ppm. ${ }^{19} \mathrm{~F}$ NMR $\left(\mathrm{CD}_{3} \mathrm{CN}, 400 \mathrm{MHz}\right) \delta-79.36 \mathrm{ppm}$. HRMS (ESI) Cald for $\left[\mathrm{C}_{32} \mathrm{H}_{24} \mathrm{~N}_{6} \mathrm{O}_{4} \mathrm{Zn}_{2}\right]^{2+}$ 343.0299, found 343.0100; Calcd for $\left[\mathrm{C}_{33} \mathrm{H}_{26} \mathrm{~F}_{3} \mathrm{~N}_{6} \mathrm{O}_{7} \mathrm{SZn}_{2}\right]^{+}$835.0118, found 835.0150. Anal. Calcd for $\mathrm{C}_{34} \mathrm{H}_{26} \mathrm{~F}_{6} \mathrm{~N}_{6} \mathrm{O}_{10} \mathrm{~S}_{2} \mathrm{Zn}_{2}: \mathrm{C}$, 41.35; H, 2.65; N, 8.51; Found C, 41.39; H. 2.92; N, 8.28.

$\left[\left(\mathbf{Z n}_{2}\left(\mathbf{L}^{2}\right)\left(\mathbf{C}_{2} \mathbf{O}_{4}\right)\right]\left(\mathbf{O}_{3} \mathbf{S C F}_{3}\right)_{2}\right.$ (compound 2) - To a $20 \mathrm{~mL}$ solution of zinc triflate (278 $\mathrm{mg}, 0.765 \mathrm{mmol})$ in $\mathrm{MeOH}$ a $20 \mathrm{~mL}$ solution of $\left[\mathrm{C}_{2} \mathrm{O}_{4}\right]\left(\mathrm{NBu}_{4}\right)_{2}(218 \mathrm{mg}, 0.383 \mathrm{mmol})$ in $\mathrm{MeOH}$ was added and allowed to stir for $5 \mathrm{~min}$ at which point a $20 \mathrm{~mL}$ solution of 2,6pyridinedicarboxalydehyde (112 $\mathrm{mg}, 0.765 \mathrm{mmol})$ was added. The resulting solution was stirred for $5 \mathrm{~min}$ at which point $m$-xylylenediamine was added $(0.110 \mathrm{~mL}, 0.765 \mathrm{mmol})$. The resulting solution was allowed to stir for $12 \mathrm{~h}$ yielding a cloudy solution. The solvent was removed under reduced pressure resulting in a white solid. This solid was then washed with $200 \mathrm{~mL}$ of THF for $1 \mathrm{~h}$. The resulting slurry was filtered and a white solid $(0.325 \mathrm{~g}, 86 \%)$ collected as pure $\left[\left(\mathrm{Zn}_{2}\left(\mathrm{~L}^{2}\right)\left(\mathrm{C}_{2} \mathrm{O}_{4}\right)\right]\left(\mathrm{O}_{3} \mathrm{SCF}_{3}\right)_{2} .{ }^{1} \mathrm{H} \mathrm{NMR}\left(\mathrm{CD}_{3} \mathrm{CN}, 400 \mathrm{MHz}\right) \delta 8.68(\mathrm{~s}, 4 \mathrm{H}) 8.41(\mathrm{t}, J=7.6 \mathrm{~Hz}, 2 \mathrm{H})\right.$, $8.077(\mathrm{~d}, J=7.2 \mathrm{~Hz}, 4 \mathrm{H}), 7.10(\mathrm{~s}, 8 \mathrm{H}), 4.87(\mathrm{~s}, 8 \mathrm{H}) \mathrm{ppm} .{ }^{13} \mathrm{C}$ NMR $\left(\mathrm{CD}_{3} \mathrm{CN}, 75 \mathrm{MHz}\right) \delta$ $168.98,160.29,146.85,145.18,136.64,130.87,130.41,130.14,130.00,62.62$ ppm. ${ }^{19} \mathrm{~F}$ NMR $\left(\mathrm{CD}_{3} \mathrm{CN}, 400 \mathrm{MHz}\right) \delta-79.35 \mathrm{ppm}$. HRMS (ESI) Calcd for $\left[\mathrm{C}_{32} \mathrm{H}_{24} \mathrm{~N}_{6} \mathrm{O}_{4} \mathrm{Zn}_{2}\right]^{2+} 343.0299$, found 
343.0222; Calcd for $\left[\mathrm{C}_{33} \mathrm{H}_{26} \mathrm{~F}_{3} \mathrm{~N}_{6} \mathrm{O}_{7} \mathrm{SZn}_{2}\right]^{+}$835.0118, found 835.0148 Anal. Calcd for $\mathrm{C}_{34} \mathrm{H}_{26} \mathrm{~F}_{6} \mathrm{~N}_{6} \mathrm{O}_{10} \mathrm{~S}_{2} \mathrm{Zn}_{2} \mathrm{C}, 41.35 ; \mathrm{H}, 2.65 ; \mathrm{N}, 8.51$; Found C, 41.09; H. 3.17; N, 8.27.

$\left[\left(\mathbf{Z n}_{2}\left(\mathbf{L}^{3}\right)\left(\mathbf{C}_{2} \mathbf{O}_{4}\right)\right]\left(\mathbf{O}_{3} \mathbf{S C F}_{3}\right)_{2}\right.$ (compound 3) - To a $20 \mathrm{~mL}$ solution of zinc triflate (278 $\mathrm{mg}, 0.765 \mathrm{mmol})$ in $\mathrm{MeOH}$ a $20 \mathrm{~mL}$ solution of $\left[\mathrm{C}_{2} \mathrm{O}_{4}\right]\left(\mathrm{NBu}_{4}\right)_{2}(218 \mathrm{mg}, 0.383 \mathrm{mmol})$ in $\mathrm{MeOH}$ was added and allowed to stir for $5 \mathrm{~min}$ at which point a $20 \mathrm{~mL}$ solution of 2,6-diacetylpyridine (125 mg, $0.765 \mathrm{mmol}$ ) was added. The resulting solution was stirred for $5 \mathrm{~min}$ at which point $\mathrm{m}$ xylylenediamine was added $(0.110 \mathrm{~mL}, 0.765 \mathrm{mmol})$. The resulting yellow solution was allowed to stir for $12 \mathrm{~h}$ yielding a orange solution. The solvent was removed under reduced pressure. The resulting orange solid was then dissolved in $10 \mathrm{~mL}$ of DMSO, and $100 \mathrm{~mL}$ of THF was then added dropwise to the DMSO solution of $\left[\left(\mathrm{Zn}_{2}\left(\mathrm{~L}^{3}\right)\left(\mathrm{C}_{2} \mathrm{O}_{4}\right)\right]\left(\mathrm{O}_{3} \mathrm{SCF}_{3}\right)_{2}\right.$ to precipitate a orange solid. The solid was collected yielding $\left[\left(\mathrm{Zn}_{2}\left(\mathrm{~L}^{3}\right)\left(\mathrm{C}_{2} \mathrm{O}_{4}\right)\right]\left(\mathrm{O}_{3} \mathrm{SCF}_{3}\right)_{2}(0.290 \mathrm{~g}, 73 \%)\right.$. X-ray quality crystals were obtained by vapor diffusion of ether into DMF. ${ }^{1} \mathrm{H}$ NMR $\left(\mathrm{CD}_{3} \mathrm{CN}, 400 \mathrm{MHz}\right) \delta$ $8.51,(\mathrm{t}, J=7.2 \mathrm{~Hz}, 2 \mathrm{H}), 8.39(\mathrm{~d}, J=7.6 \mathrm{~Hz}, 4 \mathrm{H}), 7.26(\mathrm{t}, J=8.8 \mathrm{~Hz}, 2 \mathrm{H}) 7.04(\mathrm{~m}, 6 \mathrm{H}), 4.85(\mathrm{~s}$, 8H), $2.74(\mathrm{~s}, 12 \mathrm{H}) \mathrm{ppm} .{ }^{13} \mathrm{C}$ NMR $\left(\mathrm{CD}_{3} \mathrm{CN}-\mathrm{d}_{3}, 75 \mathrm{MHz}\right) \delta 166.79,164.73,147.14,143.57$, $135.81,129.76,128.83,127.76,126.28,54.80,15.20 .{ }^{19} \mathrm{~F}$ NMR $\left(\mathrm{CD}_{3} \mathrm{CN}, 400 \mathrm{MHz}\right) \delta-77.717$

ppm. HRMS (ESI) Calcd for $\left[\mathrm{C}_{36} \mathrm{H}_{34} \mathrm{~N}_{6} \mathrm{O}_{4} \mathrm{Zn}_{2}\right]^{2+}$ 371.0612, found 371.0591; Calcd for $\left[\mathrm{C}_{38} \mathrm{H}_{34} \mathrm{~N}_{6} \mathrm{O}_{7} \mathrm{~F}_{3} \mathrm{SZn}_{2}\right]^{+}$891.0734, found 891.0781. Anal. Calcd for $\mathrm{C}_{38} \mathrm{H}_{38} \mathrm{~F}_{6} \mathrm{~N}_{6} \mathrm{O}_{10} \mathrm{~S}_{2} \mathrm{Zn}_{2} \cdot 3 \mathrm{H}_{2} \mathrm{O} \mathrm{C}$, 40.26; H, 3.91; N, 7.41; Found C, 40.02; H, 3.90; N, 7.21.

\section{Attempt to synthesize di-zinc complex with p-xylyldiamine and 2,6-diacetylpyridine}

- To a $20 \mathrm{~mL}$ solution of zinc triflate $(278 \mathrm{mg}, 0.765 \mathrm{mmol})$ in $\mathrm{MeOH}$ a $20 \mathrm{~mL}$ solution of $\left[\mathrm{C}_{2} \mathrm{O}_{4}\right]\left(\mathrm{NBu}_{4}\right)_{2}(218 \mathrm{mg}, 0.383 \mathrm{mmol})$ in $\mathrm{MeOH}$ was added and allowed to stir for $5 \mathrm{~min}$ at which point a $20 \mathrm{~mL}$ solution of 2,6-diacetylpyridine (125 mg, $0.765 \mathrm{mmol}$ ) was added. The resulting solution was stirred for $5 \mathrm{~min}$ 
at which point $p$-xylylenediamine was added $(104 \mathrm{mg}, 0.765 \mathrm{mmol})$. The resulting yellow solution was allowed to stir for $12 \mathrm{~h}$ yielding a yellow slurry. The solvent was then removed. The resulting solid was insoluble in all conventional organic solvents. (i. e. THF, $\left.\mathrm{CH}_{3} \mathrm{CN}, \mathrm{DMF}, \mathrm{DMSO}, \mathrm{MeOH}\right)$

$\left[\left(\mathbf{Z n}_{2}\left(\mathbf{L}^{\mathbf{4}}\right)\left(\mathbf{C}_{\mathbf{2}} \mathbf{O}_{4}\right)\right]\left(\mathbf{O}_{3} \mathbf{S C F}_{3}\right)_{2}\right.$ (compound 4) - To a $20 \mathrm{~mL}$ solution of zinc triflate (332 $\mathrm{mg}, 0.912 \mathrm{mmol})$ in $\mathrm{MeOH}$ a $20 \mathrm{~mL}$ solution of $\left[\mathrm{C}_{2} \mathrm{O}_{4}\right]\left(\mathrm{NBu}_{4}\right)_{2}(261 \mathrm{mg}, 0.456 \mathrm{mmol})$ in $\mathrm{MeOH}$ was added and allowed to stir for $5 \mathrm{~min}$ at which point a $20 \mathrm{~mL}$ solution of 3-tert-butyl-2,6diacetylpyridine (200 mg, $0.912 \mathrm{mmol}$ ) was added. The resulting solution was stirred for $5 \mathrm{~min}$ at which point $m$-xylylenediamine was added $(0.121 \mathrm{~mL}, 0.912 \mathrm{mmol})$. The resulting yellow solution was allowed to stir for $12 \mathrm{~h}$ yielding an orange solution. The solvent was removed under reduced pressure. The resulting orange solid was then washed with $100 \mathrm{~mL}$ of THF. The solid was then collected by filtration yielding pure $\left[\left(\mathrm{Zn}_{2}\left(\mathrm{~L}^{4}\right)\left(\mathrm{C}_{2} \mathrm{O}_{4}\right)\right]\left(\mathrm{O}_{3} \mathrm{SCF}_{3}\right)_{2}(1.01 \mathrm{~g}, 96 \%) .{ }^{1} \mathrm{H} \mathrm{NMR}\right.$ $\left(\mathrm{CD}_{3} \mathrm{OD}, 400 \mathrm{MHz}\right) \delta 8.39(\mathrm{~s}, 4 \mathrm{H}), 7.32(\mathrm{~s}, 2 \mathrm{H}) ; 7.26(\mathrm{~d}, J=7.2 \mathrm{~Hz}, 4 \mathrm{H}), 7.02(\mathrm{~s}, 2 \mathrm{H}), 3.85$ (s, 8H), $2.80(\mathrm{~s}, 12 \mathrm{H}), 1.52(\mathrm{~s}, 18 \mathrm{H}) \mathrm{ppm} .{ }^{13} \mathrm{C} \mathrm{NMR}\left(\mathrm{CD}_{3} \mathrm{OD}, 75 \mathrm{MHz}\right) \delta 167.39,149.44,137.62$, $131.02,142.85,124.71,123.95,120.40,69.03,56.69,30.83,26.65$ ppm. ${ }^{19} \mathrm{~F}$ NMR $\left(\mathrm{CD}_{3} \mathrm{CN}, 400\right.$ MHz) $\delta$-79.919 ppm. HRMS (ESI) Calcd for $\left[\mathrm{C}_{44} \mathrm{H}_{48} \mathrm{~N}_{6} \mathrm{O}_{4} \mathrm{Zn}_{2}\right]^{2+} 427.1238$, found 427.1094; Calcd for $\left[\mathrm{C}_{45} \mathrm{H}_{50} \mathrm{~N}_{6} \mathrm{O}_{7} \mathrm{~F}_{3} \mathrm{SZn}_{2}\right]^{+}$1003.1996, found 1003.2043.

Attempt to synthesize $\left[\left(\mathrm{Zn}_{2}\left(\mathrm{~L}^{\mathbf{3}}\right)\right]\left(\mathrm{O}_{3} \mathrm{SCF}_{3}\right)_{4}\right.$ in the absence of oxalate - To a $20 \mathrm{~mL}$ solution of zinc triflate $(278 \mathrm{mg}, \quad 0.765 \mathrm{mmol})$ in $\mathrm{MeOH}$ was added a $10 \mathrm{~mL}$ solution of 2,6-diacetylpyridine (125 mg, $0.765 \mathrm{mmol})$ in $\mathrm{MeOH}$. The resulting solution stirred for $5 \mathrm{~min}$ before the addtion of $m$-xylenediamine (0.110 mL, 0.765, mmol). The mixture was allowed to stir for $16 \mathrm{~h}$. The 
solvent was then removed under reduced pressure resulting in an orange wax. ${ }^{1} \mathrm{H}$ NMR of the product showed no peaks corresponding to the desired product.

Attempt at the synthesis of di-Zn bridged macrocycles with other (formate/acetate/malonate/succinate) templates - To a $20 \mathrm{~mL}$ solution of zinc triflate $(278$ $\mathrm{mg}, 0.765 \mathrm{mmol}$ ) in $\mathrm{MeOH}$ a $15 \mathrm{~mL}$ solution of $\mathrm{HCO}_{2} \mathrm{~K} / \mathrm{CH}_{3} \mathrm{CO}_{2} \mathrm{~K}_{/} \mathrm{K}_{2} \mathrm{CO}_{2} \mathrm{CH}_{2} \mathrm{CO}_{2} / \mathrm{C}_{4} \mathrm{H}_{6} \mathrm{O}_{4} \mathrm{Na}_{2}$ $(32.2 / 38.0 / 68.3 / 62.0 \mathrm{mg}, 0.383 \mathrm{mmol})$ in $\mathrm{MeOH}$ was added and allowed to stir for $5 \mathrm{~min}$ at which point a $20 \mathrm{~mL}$ solution of 2,6-diacetylpyridine $(125 \mathrm{mg}, 0.765 \mathrm{mmol})$ was added. The resulting solution was stirred for $5 \mathrm{~min}$ at which point $m$-xylylenediamine was added $(0.110 \mathrm{~mL}$, $0.765 \mathrm{mmol})$. The resulting yellow solution was allowed to stir for $24 \mathrm{~h}$ yielding an orange heterogeneous mixture. The resulting mixture was then filtered to collect an orange solid, which was only sparingly soluble in DMSO or DMF. A ${ }^{1} \mathrm{H}$ NMR spectrum collected in DMSO- $\mathrm{d}_{6}$ shows no resonances within the 1-12 ppm window. No peaks for any expected products were observed by ESI-MS.

$\left[\left(\mathbf{Z n}_{2}\left(\mathbf{L}^{3}\right)\left(\mathbf{C}_{\mathbf{2}} \mathbf{O}_{4}\right) \mathbf{B r}_{2}\right]\right.$ (compound 5) - A $10 \mathrm{~mL}$ solution of $\mathrm{CaBr}_{2}(370 \mathrm{mg}, 1.86 \mathrm{mmol})$ in DMSO was added to a stirring $30 \mathrm{~mL}$ solution of $\left[\left(\mathbf{Z n}_{\mathbf{2}}\left(\mathbf{L}^{\mathbf{3}}\right)\left(\mathbf{C}_{\mathbf{2}} \mathbf{O}_{\mathbf{4}}\right)\right]\left(\mathbf{O}_{\mathbf{3}} \mathbf{S C F}\right)_{\mathbf{2}}\right.$ (compound $\mathbf{3}$, $485 \mathrm{mg}, 0.465 \mathrm{mmol}$ ) in DMSO. The resulting orange solution was allowed to stir for $24 \mathrm{~h}$. To the solution was added $200 \mathrm{~mL}$ of THF to precipitate an orange solid that was then collected. Xray quality crystals (67 mg obtained, $16 \%$ yield) were obtained by vapor diffusion of ether into a concentrated DMSO solution. ${ }^{1} \mathrm{H}$ NMR $\left(D_{M S O}-d_{6}\right) 8.61$ (t, J=6.8 Hz, 2H), 8.56 (d, J=6.8 Hz, 4H); $7.22(\mathrm{t}, J=7.6 \mathrm{~Hz}, 2 \mathrm{H}) ; 6.70(\mathrm{~d}, J=7.6 \mathrm{~Hz}, 4 \mathrm{H}) ; 6.92(\mathrm{~s}, 2 \mathrm{H}) ; 4.81(\mathrm{~s}, 8 \mathrm{H}), 2.77(\mathrm{~s}, 12 \mathrm{H})$ ppm. HRMS (ESI) Calcd for $\left[\mathrm{C}_{36} \mathrm{H}_{34} \mathrm{BrN}_{6} \mathrm{O}_{4} \mathrm{Zn}_{2}\right]^{+}, 821.0408$; Found, 821.0231. 
The reaction of $\left[\left(\mathrm{Zn}_{2}\left(\mathrm{~L}^{3}\right)\left(\mathbf{C}_{2} \mathbf{O}_{4}\right)\right]\left(\mathrm{O}_{3} \mathrm{SCF}_{3}\right)_{2}\right.$ with Acetic Acid - To a stirring solution of $\left[\left(\mathrm{Zn}_{2}\left(\mathrm{~L}^{3}\right)\left(\mathrm{C}_{2} \mathrm{O}_{4}\right)\right]\left(\mathrm{O}_{3} \mathrm{SCF}_{3}\right)_{2}(50.0 \mathrm{mg}, 0.479 \mathrm{mmol})\right.$ in $\mathrm{CH}_{3} \mathrm{CN}$ was added $0.01 \mathrm{~mL}$ of concentrated acetic acid. The resulting solution was allowed to stir for $24 \mathrm{~h}$. The ${ }^{1} \mathrm{H}$ NMR spectrum showed no that no reaction had occurred.

The reaction of $\left[\left(\mathrm{Zn}_{2}\left(\mathrm{~L}^{3}\right)\left(\mathrm{C}_{2} \mathrm{O}_{4}\right)\right]\left(\mathrm{O}_{3} \mathrm{SCF}_{3}\right)_{2}\right.$ with $\mathrm{HCl}$ - To a stirring solution of $\left[\left(\mathrm{Zn}_{2}\left(\mathrm{~L}^{3}\right)\left(\mathrm{C}_{2} \mathrm{O}_{4}\right)\right]\left(\mathrm{O}_{3} \mathrm{SCF}_{3}\right)_{2}(50.0 \mathrm{mg}, 0.479 \mathrm{mmol})\right.$ in $\mathrm{CH}_{3} \mathrm{CN}$ was added approximately 4 equivalents of $1.00 \mathrm{M} \mathrm{HCl}$ in $\mathrm{CH}_{3} \mathrm{CN}$. The ${ }^{1} \mathrm{H}$ NMR spectrum demonstrated formation of a mixture of products. An aliquot of the resulting solution was then injected into the mass spectrometer, to show formation of " $\left[\left(\mathrm{Zn}_{2}\left(\mathrm{~L}^{3}\right)(\mathrm{Cl})_{3}\left(\mathrm{OH}_{2}\right)\right]\left(\mathrm{O}_{3} \mathrm{SCF}_{3}\right.\right.$ )" (compound 6) observed as $\left[\left(\mathrm{Zn}_{2}\left(\mathrm{~L}^{3}\right)(\mathrm{Cl})_{3}\left(\mathrm{OH}_{2}\right)\right]^{+}\right.$. ESI MS Calcd for $\left[\mathrm{C}_{34} \mathrm{H}_{36} \mathrm{~N}_{6} \mathrm{OZn}_{2} \mathrm{Cl}_{3}\right]^{+}, 777.0599$. Found, 777.0700.

\section{References}

[1] (a) Thomas, C. M. Comments Inorg. Chem. 2011, 32, 14-38. (b) Cooper, B. G.; Napoline, J. W.; Thomas, C. M. Catalysis Reviews: Science and Engineering 2012, 54, 1-40.

[2] For selected recent examples, see: (a) Y. Lee, F. T. Sloane, G. Blondin, K. A. Abboud, R. García-Serres, L. J. Murray, Angew. Chem. Int. Ed. 2015, 54, 1499-1503. (b) L. J. Murray, W.

W. Weare, J. Shearer, A. D. Mitchell, K. A Abboud, J. Am. Chem. Soc. 2014, 136, 13502-13505.

(c) S. Pal, C. Uyeda, J. Am. Chem. Soc. 2015, 137, 8042-8045. (d) S. Suseno, C. C. L. McCrory, R. Tran, S. Gul, J. Yano, T. Agapie, Chem. Eur. J. 2015, 21, 13420-13430. (e) S. Kuppuswamy, T. R. Cass, M. W. Bezpalko, B. M. Foxman, C. M. Thomas, Inorg. Chim. Acta 2015, 424, 167172. (f) T. M. Powers, T. A. Betley, J. Am. Chem. Soc. 2013, 135, 12289. (g) P. A. Rudd, N. Planas, E. Bill, L. Gagliardi, C. C. Lu, Eur. J. Inorg. Chem. 2013, 3898-3906. 
[3] X. Zhang, D.Huang, Y.-S. Chen, R. H. Holm, Inorg. Chem. 2012, 51, 11017-11029. (b) D. Huang, R. H. Holm, J. Am. Chem. Soc. 2010, 132, 4693-4701. (c) B. D. Neisen, P. Solntsev, M. R. Halvagar, W. B. Tolman, Eur. J. Inorg. Chem. 2015, DOI: 10.1002/ejic.201501060. (d) M. R. Halvagar, B. Neisen, W. B. Tolman, Inorg. Chem. 2013, 52, 793-799.

[4] (a) P. A. Vigato, S. Tamburini, Coord. Chem. Rev. 2004, 248, 1717-2128. (b) P. A. Vigato, S. Tamburini, L. Bertolo, Coord. Chem. Rev. 2007, 251, 1311-1492. (c) N. V. Gerbeleu, V. B. Arion, J. Burgess, Ch. 3, "Template synthesis of macrocyclic systems based on di- and polyamines and polyfunctional dicarbonyl compounds, In "Template Synthesis of Macrocyclic Compounds", WILEY-VCH Verlag GmbH. D-69469 Weinheim (Federal Republic of Germany), 1999.

[5] For selected examples, see: (a) S. S. Tandon, L. K. Thompson, J. N. Bridson, M. Bubenik, Inorg. Chem. 1993, 32, 4621-4631; (b) M. G. B. Drew, J. Hunter, D. J. Marrs, J. Nelson, C. Harding, J. Chem. Soc., Dalton Trans. 1992, 3235-3242; (c) M. Mikuriya, T. Tuyii, T. Tokii, A. Kawamori, Bull. Chem. Soc. Jpn. 1993, 66, 1675-1686; (d) Q. Lu, J.-M. Latour, C. J. Harding, N. Martin, D.J. Marrs, V. McKee, J. Nelson, J. Chem. Soc., Dalton Trans. 1994, 1471-1478.

[6] (a) C. A. Salata, M. T. Youinou, C. J. Burrows, J. Am. Chem. Soc. 1989, 111, 9278-9279. (b) C. A. Salata, M. T. Youinou, C. J. Burrows, Inorg. Chem. 1991, 30, 3454-3461.

[7] (a) A. Bheemaraju, R. L. Lord, P. Müller, S. Groysman, Organometallics 2012, 31, 21202123; (b) A. Bheemaraju, J. W. Beattie, R. L. Lord, P. D. Martin, S. Groysman, Chem. Commun. 2012, 48, 9595-9597; (c) A. Bheemaraju, J. W. Beattie, E. G. Tabasan, P. D. Martin, R. L. Lord, S. Groysman, Organometallics 2013, 32, 2952-2962; (d) J. W. Beattie, D. S. White, A. Bheemaraju, P. D. Martin, S. Groysman, Dalton Trans. 2014, 43, 7979-7986. (e) A. Bheemaraju, 
J. W. Beattie, Y. Danylyuk, J. Rochford, S. Groysman, Eur. J. Inorg. Chem. 2014, 34, 58655873. (f) B. R. Reed, S. A. Stoian, R. L. Lord, S. Groysman, Chem. Commun. 2015, 51, 64966499.

[8] S. Nuckel, P. Burger, Organometallics 2001, 20, 4345 - 4359.

[9] (a) S. P. Foxon, O. Walter, R. Koch, H. Rupp, P. Müller, S. Schindler, Eur. J. Inorg. Chem. 2004, 344-348; (b) M. Hu, G. Feng, Chem. Commun. 2012, 48, 6951-6953; (c) M. M. Rhaman, F. R. Fronczek, D. R. Powell, M. A. Hossain, Dalton Trans. 2014, 43. 4618-4621; (d) L. Tang, J. Park, H.-J. Kim, Y. Kim, S. J. Kim, J. Chin, K. M. Kim, J. Am. Chem. Soc. 2008, 130, 1260612607; (e) P. Mateus, R. Delgado, P. Brandão, V. Félix, Chem. Eur. J. 2011, 17, 7020-7031.

[10] For selected examples of crystallographically characterized Zn-O bonds, see: (a) S. Groysman, E. Sergeeva, I. Goldberg, M. Kol, Eur. J. Inorg. Chem. 2006, 2739-2745. (b) K. Yamada, S. Yagishita, H. Tanaka, K. Tohyama, K. Adachi, S. Kaizaki, H. Kumagai, K. Inoue, R. Kitaura, H.-C. Chang, S. Kitagawa, S. Kawata, Chem. Eur. J. 2004, 10, 2647-2660. (c) S. A. Cantalupo, S. R. Fiedler, M. P. Shores, A. L. Rheingold, L. H. Doerrer, Angew. Chem. Int. Ed. 2012, 51, 1000-1005.

[11] For selected examples of crystallographycally characterized $\mathrm{Zn}-\mathrm{N}$ bonds, see: (a) J. R. Thompson, J. S. Ovens, V. E. Williams, D. B. Leznoff, Chem. Eur. J. 2013, 19, 16572 - 16578. (b) T. Moriuchi, M. Nishiyama, T. Hirao, Eur. J. Inorg. Chem. 2002, 447 - 451. (c) O. R. Luca, S. J. Konezny, E. K. Paulson, F. Habib, K. M. Luthy, M. Murugesu, R. H. Crabtree, V. S. Batista, Dalton Trans. 2013, 42, 8802-8807.

[12] J. Vela, L. Zhu, C. J. Flaschenriem, W. W. Brennessel, R. J. Lachicotte, P. L. Holland, Organometallics 2007, 26, 3416-3423. 
[13] For the recent review on redox-active ligands, see: K. G. Caulton, Eur. J. Inorg. Chem. $2012,435-443$.

[14] For selected examples of Zn complexes in redox-active environments, see: (a) C. C. Lu, E. Bill, T. Weyhermüller, E. Bothe, K. Wieghardt, J. Am. Chem. Soc. 2008, 130, 3181-3197. (b) P. Banerjee, A. Company, T. Weyhermüller, E. Bill, C. R. Hess, Inorg. Chem. 2009, 48, 29442955. (c) N. Komine, R. W. Buell, C.-H. Chen, A. K. Hui, M. Pink, K. G. Caulton, Inorg. Chem. 2014, 53, 1361-1369. (d) P. Chaudhuri, M. Hess, K. Hildenbrand, E. Bill, T. Weyhermüller, K. Wieghardt, Inorg. Chem. 1999, 38, 2781-2790.

[15] T. W. Myers, T. J. Sherbow, J. C. Fettinger, L. A. Berben, Dalton Trans. 2015, 44, Advance article.

[16] (a) F. Kanoufi, A. J. Bard, J. Phys. Chem. B 1999, 103, 47, 10469-10480. (b) M.-C. Lu, C.W. Whang, Anal. Chim. Acta 2004, 522, 25-33.

[17] For the discussion on possible topologies of oxalate coordination to transition metals, see: M. Hernández-Molina, P. A. Lorenzo-Luis, C. Ruiz-Pérez, CrystEngComm 2001, 16, 1-4. 
TOC entry: oxalate template, macrocyclic compounds

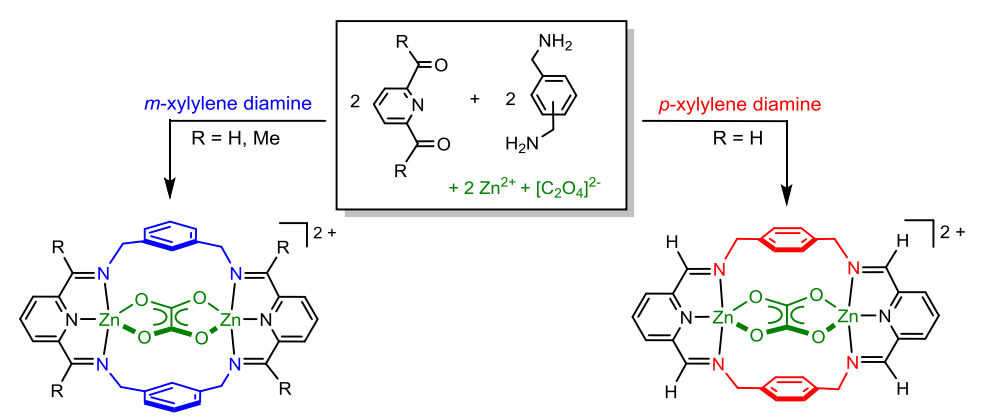

Oxalate serves as a template in the formation of di-zinc Schiff-base macrocycles linked by $p$ - or $m$-xylylenes. NMR spectroscopy and X-ray crystallography both demonstrate symmetric structures containing $\mu^{2}-\kappa^{2}, \kappa^{2}$ oxalate. Treatment of one of the compounds with $\mathrm{CaBr}_{2}$ transforms bridging oxalate into the asymmetric $\mu^{2}-\kappa^{1}, \kappa^{2}$ form. The use of $\mathrm{HCl}$ enables oxalate removal as observed by ESI-MS. 